\title{
Optimization of Distribution System Reliability
}

\author{
L. Zemite, J. Gerhards, M. Gorobetz, A. Levchenkov
}

\begin{abstract}
- reliability analysis of distribution systems has been attracting increasing attention. A special concern pertains to the distribution networks on which most failures occurs. The optimization of distribution system of breakers and power switches is a possible strategy to improve reliability. The paper describes development procedure for modelling restoring after a fault and calculating associated reliability indices and customers' outage costs. The developed model of the network and reliability and outage costs calculating algorithm is suitable for multi-criteria analysis of the network. Proposed reliability and outage costs calculation algorithm is based on Monte Carlo simulation and genetic algorithm.
\end{abstract}

Index Terms - distribution network, simulation, power supply reliability.

\section{INTRODUCTION}

$\mathrm{W}$ ith the development of economy and mankind the electric distribution networks and technical and technological solutions of the equipment connected to them are also changing resulting in the changes of its application opportunities and requirements to quality of the supplied energy.

Taking into account the conditions of the free market and increasing demands of the customers in an uninterrupted electric power supply the effectiveness of capital investments are expected to be determined as well as losses resulted from the supply interruptions and electric supply reliability should be calculated.

The basic task of an electric supply network operator is to provide a customer with energy supply of a necessary level of reliability and quality with as low financial expenses as possible.

The evaluation of interruptions risks of an electric supply system requires to know structure of the network, its load and customers data [1].

\section{METHODS FOR CALCULATION OF THE LOSSES RESULTED FROM THE ELECTRIC SUPPLY INTERRUPTIONS}

The losses resulted from the electric supply interruptions that have economic and social influence on the society can be divided into direct and indirect losses.

Direct losses are connected with undelivered electric energy. Indirect losses are not connected with the interruptions themselves but with their consequences.
Different types of losses calculations depend on different durations of interruptions, distribution of the customers' groups, methods of results calculations, methods of data obtaining, etc. [2,3].

According to the calculation types the methods of losses calculation can be divided into three subgroups - analytical, simulation and methods of customers' interview $[2,3]$.

After choice of methods - analytical, simulation or interview, the direct and indirect losses resulted from interruptions should be analyzed and calculated.

The factors influencing the reliability can be divided into subgroups according to the customers of electric energy, undelivered energy or power, duration of interruptions, frequency as well as combining these subgroups in different ways.

The customers groups are divided taking into account equal electric energy consumption and equal interruption losses (Fig.1.) [4].

Methodology of calculation of electric supply losses from interruptions The values of the electric supply reliability and losses resulted from the interruptions are calculated with the accounting of the following factors: structure of electric supply

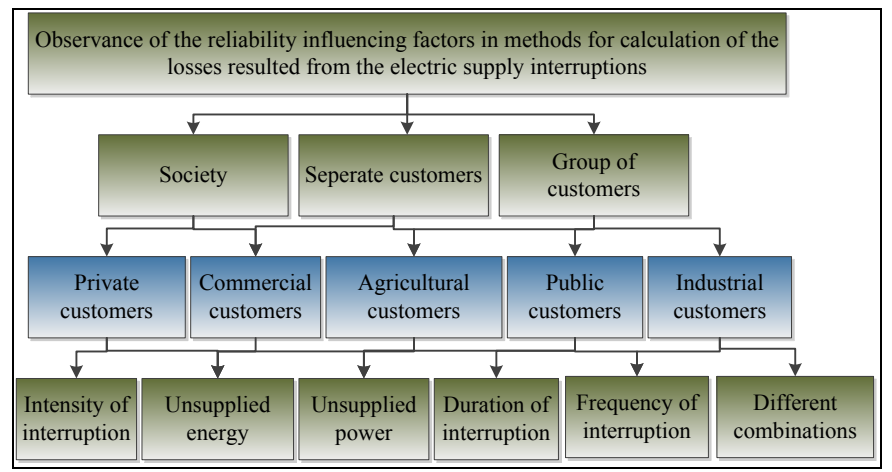

Fig. 1. Factors influencing the losses from electric supply interruptions.

network, undelivered electric energy, distribution functions of the interruptions durations probabilities, the duration of electric supply system interruptions elimination for reserved, unreserved and auxiliary elements as well as the losses of the network, society and customers resulted from the interruption $[5,6,7]$.

The purpose of the calculations is to consider different scenarios as well as to calculate the losses form the interruptions.

For the calculation of the losses the following tasks are 
defined:

- to model the network and select the criteria for reliability and from interruptions resulted losses;

- to provide an opportunity to calculate the losses resulted from the electric supply interruptions;

- to develop the methods for calculations of losses resulted from the interruptions for different periods of time and models of network taking into account consumption of electric energy, loading factor, length of the line, structure of the network, number of the customers, expenses for the interruptions elimination and capital investments, etc. and analyze the obtained results.

In the calculations of total losses for different scenarios for the analysis of capital investments scenario the several factors considered in the multi-criteria analysis are taken into account (Fig.2.) $[4,8]$.

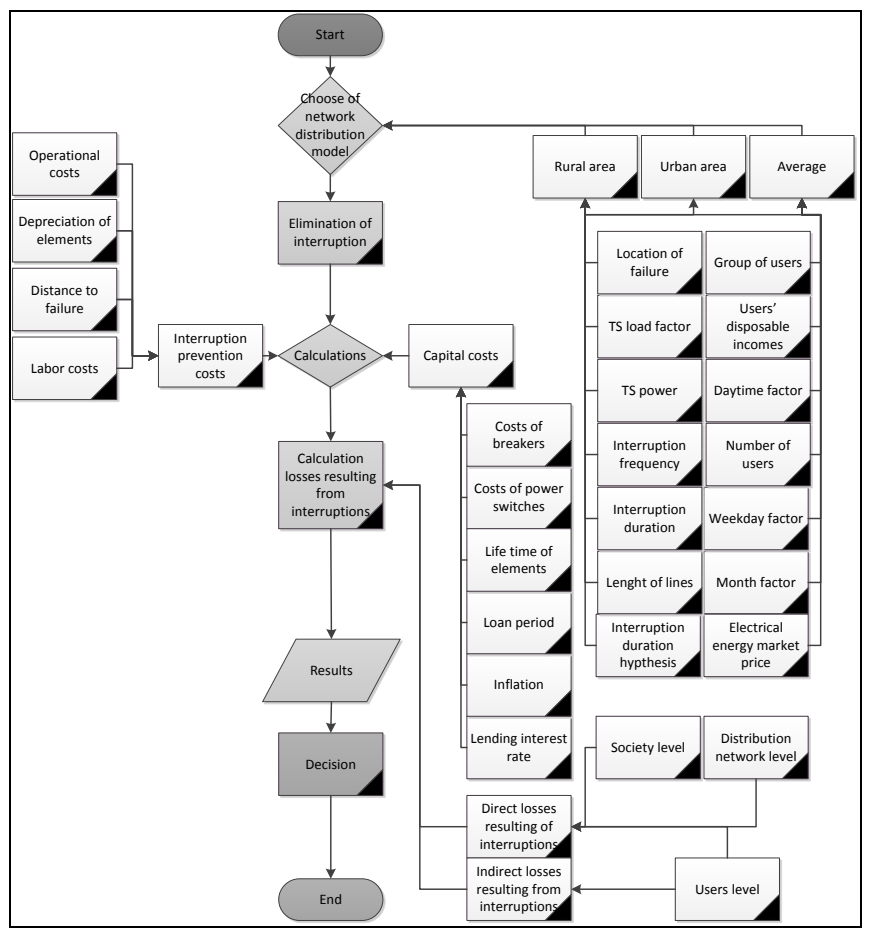

Fig. 2. Multi-criteria analysis of calculation of electric supply reliability and losses resulted from interruptions.

$20 \mathrm{kV}$ distribution network of Latvia is analyzed in details and calculated. It resulted in a developed model of network the data determined below (Fig.3.).

The reservation of electric supply is possible along the connecting line for supply sources A2, A3 and A4.

In normal regime the power switches QF1, QF5, QF3 are in on condition.

In normal regime power switches QF4 and QF2 are in off condition. Points 16, QF4 and QF5 are distribution places.

In general case for a particular group of customers the losses resulted from the interruptions depend on the number of customers $(\mathrm{N})$, on the month fm(t), on the day of a week fn(t), and time of a day $\mathrm{fh}(\mathrm{t})$. Thus the average incomes of the correspondent customers $\mathrm{C}(\mathrm{d})$ ( $€$ /year) and td - duration of interruptions, $\mathrm{h}(1)[3]$
$\operatorname{ECOST}(t, N, d)=\mathrm{N} \cdot \mathrm{f}_{m}(\mathrm{t}) \cdot \mathrm{f}_{n}(\mathrm{t}) \cdot \mathrm{f}_{h}(\mathrm{t}) \cdot \mathrm{C}(\mathrm{d}) \cdot \mathrm{t}_{d}$

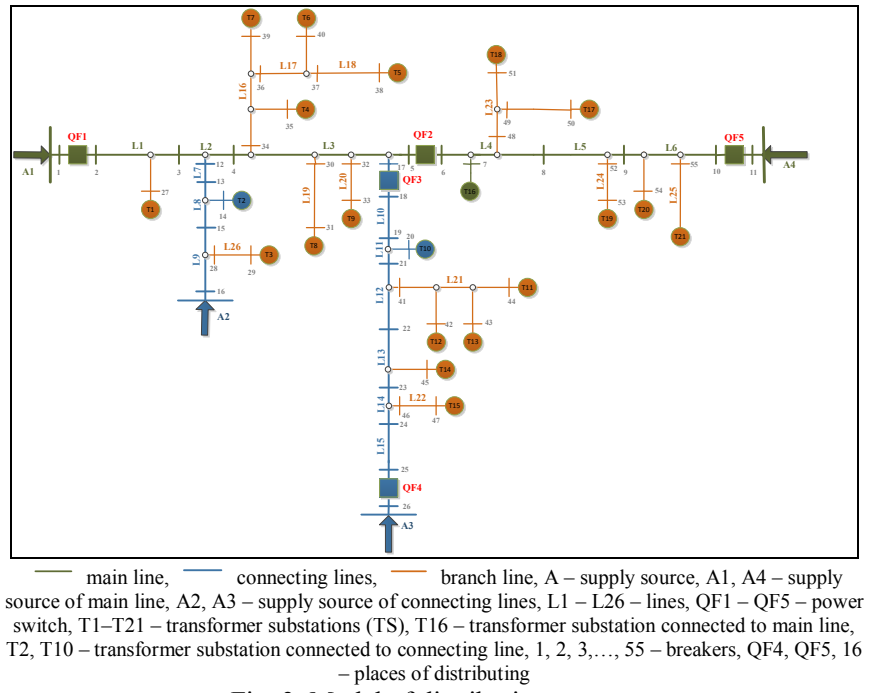

Fig. 3. Model of distribution system.

For the determining of the efficiency of the planned capital investments in the network with several possible solutions that can change the model of the network, the economic calculations are required.

While calculating the level of the losses from interruptions and capital investments the capital investments expenses, ageing of the elements and the expenses for the elimination of the supply system interruptions.

The expenses are formed from (2), where $\mathrm{C}$ - losses from interruptions during the calculation period, $€$ /year, $\mathrm{Cki}$ - capital investments expenses, $€$ /year, $\mathrm{CANi}$ - interruptions elimination expenses, $€ /$ year, CEUi - direct and indirect losses of the customers, $€$ /year, $\mathrm{n}$ - number of new elements, $\mathrm{m}$ - number of customers [8]

$$
\mathrm{C}=\sum_{\mathrm{i}=1}^{\mathrm{n}} \mathrm{C}_{\mathrm{ki}}+\sum_{\mathrm{i}=1}^{\mathrm{m}} \mathrm{C}_{\mathrm{EUi}}+C_{A N} \rightarrow \min .
$$

\section{DESCRIPTIONS OF CALCULATION OF ELECTRIC SUPPLY RELIABILITY AND LOSSES FROM INTERRUPTIONS}

A - Star algorithm is a heuristic method for the way search in given graph. The algorithm detects whether there way from the starting point to the end point.

There are developed algorithm modifications, which are intended for checking whether the customer is connected to a power source. In the algorithm modifications there are taken into account in additional restrictions - the reserve source searching in the case of network element interruption in accordance with network node positions [9].

If to take into account the features of the network structure according to a particular customer it is possible to obtain a more accurate duration of the interruptions and frequency for each customer. 
Reservation the elements of electric supply can be divided into 3 basic groups - unreserved, reserved and auxiliary.

Reservation the elements of electric supply can be divided into 3 basic groups - unreserved, reserved and auxiliary.

Unreserved elements are those which in case of interruptions customers cannot be provided with electric supply along the lines or from other sides.

Reserved elements are those which in the case of interruptions customers can be supplied from other sides.

Auxiliary elements are the elements that in case of interruptions for customers can restore electric supply for the element under consideration, as soon as interrupted element is interrupted [9].

The frequency of the elements interruptions regarding to the considered transformer substations (TS) can be found as (3), where $\omega N[x]$ - frequency of failures of unreserved elements, $\omega_{T A}[x]-$ frequency of failures of unreserved TS, $\omega N_{\text {lin }}[x]-$ frequency of failures of unreserved lines, $\omega N_{A T}[x]$ - frequency of failures of unreserved breakers, $\omega N_{J S}[x]$ - frequency of failures of unreserved power switches, $\omega R[x]$ - frequency of failures of reserved elements, $\omega R_{l i n}[x]$ - frequency of failures of reserved lines, $\omega R_{A T}[x]-$ frequency of failures of reserved breakers, $\omega R_{J S}[x]-$ frequency of failures of reserved power switches, $\omega P[x]$ - frequency of failures of auxiliary elements, $\omega P_{l i n}[x]$ - frequency of failures of auxiliary lines, $\omega P_{A T}[x]-$ frequency of failures of auxiliary breakers, $\omega P_{J S}[x]-$ frequency of failures of auxiliary power switches:

$$
\left\{\begin{array}{l}
\omega N[x]=\omega_{T A}[x]+\omega N_{\text {lin }}[x]+\omega N_{A T}[x]+\omega N_{J S}[x], \\
\omega R[x]=\omega R_{\text {lin }}[x]+\omega R_{A T}[x]+\omega R_{J S}[x] \\
\omega P[x]=+\omega P_{\text {lin }}[x]+\omega P_{A T}[x]+\omega P_{J S}[x] .
\end{array}\right.
$$

The total frequency of failures of the elements interruptions is calculated with (4)

$$
\omega[x]=\omega N[x]+\omega R[x]+\omega P[x] .
$$

The total frequency of the elements interruptions $a[x]$ can be calculated as (5), where $a N[x]$ - number unreserved elements, $a R[x]$ - number reserved elements, $a P[x]$ - number of auxiliary elements

$$
a[x]=a N[x]+a R[x]+a P[x] .
$$

The total duration of the elements interruptions $\tau[x]$ is (6), where $t N$ - duration of interruption of unreserved elements, $t R$ - duration of interruption of reserved elements, $t P-$ duration of interruption of auxiliary elements

$$
\tau[x]=a N[x] \cdot t N+a R[x] \cdot t R+a P[x] \cdot t P .
$$

\section{A. Calculations of interrupted energy assessment rate}

The statistical data of several countries were compared, the calculated interrupted energy assessment rate (IEAR) was determined for all groups of customers; the values of maximum and minimum undelivered electric energy were calculated [10].

\section{B. Calculations of losses from interruptions by Monte Carlo method}

The electric supply reliability and the losses resulted from the electric supply interruption for the models with additional manually indicated localizations of power switches are calculated on the basis of Monte Carlo modelling method.

The calculations take into account the analysis of the factors influencing the reliability for the urban and rural areas electric supply network models as well as for the average model with the purpose to calculate the expected duration of the interruptions without the analysis of previous power switches localizations $[8,11]$.

\section{Calculations of losses from interruptions by genetic} algorithm with optimized numbers and localizations of power switches

The optimization of the number and localization of the power switches is realized with the help of genetic algorithm (GA), taking into account capital expenses and the expenses of elimination of supply system interruption $[8,10,12]$.

The calculation of losses from interruptions according to the number and localization of additionally placed power switches in main lines and connection lines is realized with the aim to define an optimal number and localization of power switches taking into account the capital investments for power switches [10].

D. Calculations of losses from interruptions by genetic algorithm with optimized numbers and localizations of breakers

The criteria of the optimization of the power switches resulted in the decision to optimize the breakers in the main lines and connecting lines, taking into account the expenses of the capital investments and interruptions elimination.

The optimization of the number and localization of breakers in main and connecting lines is realized with the help of genetic algorithm for the electric supply network models of rural area, urban area and average type.

Capital investments and expenses for the interruptions elimination without loan, for the loan period of 10 years and for the loan period of 25 years.

\section{RESULTS OF CALCULATIONS OF ELECTRIC SUPPLY LOSSES RESULTED FROM INTERRUPTIONS}

\section{A. A. Results of interrupted energy assessment rate}

IEAR calculated for an average electric supply network model is demonstrated in Fig. 4. 
IEAR calculated for an electric supply network model in rural areas is demonstrated in Fig. 5.

IEAR calculated for an urban electric supply network model is demonstrated in Fig. 6.

The summarized data show that the losses from the

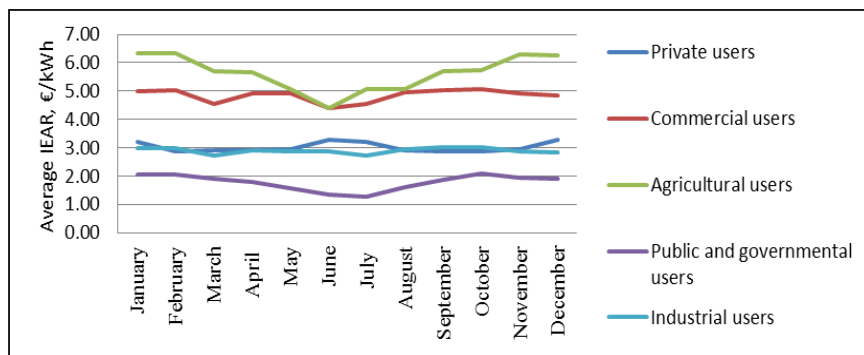

Fig. 4. Average IEAR.

interruptions in $20 \mathrm{kV}$ electric supply network in Latvia are equivalent to those in Finland, Norway, the Netherlands, USA

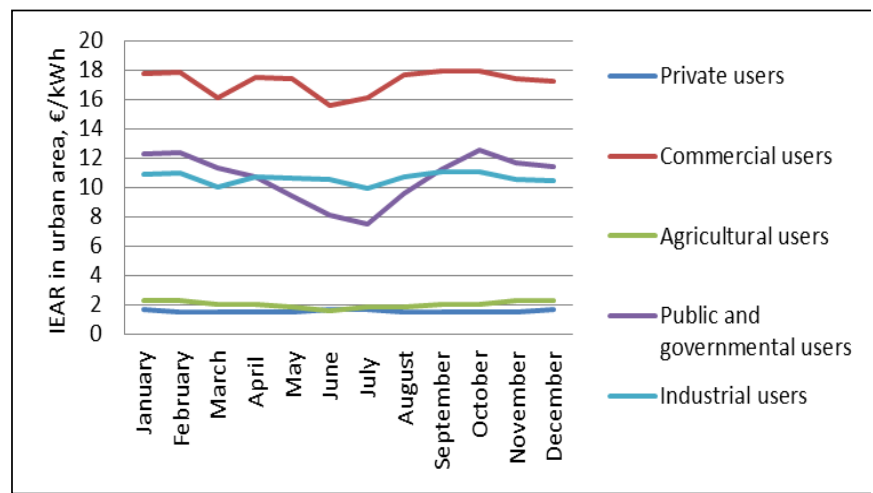

Fig. 5. IEAR in a rural area.

and Sweden $[4,11,13]$.

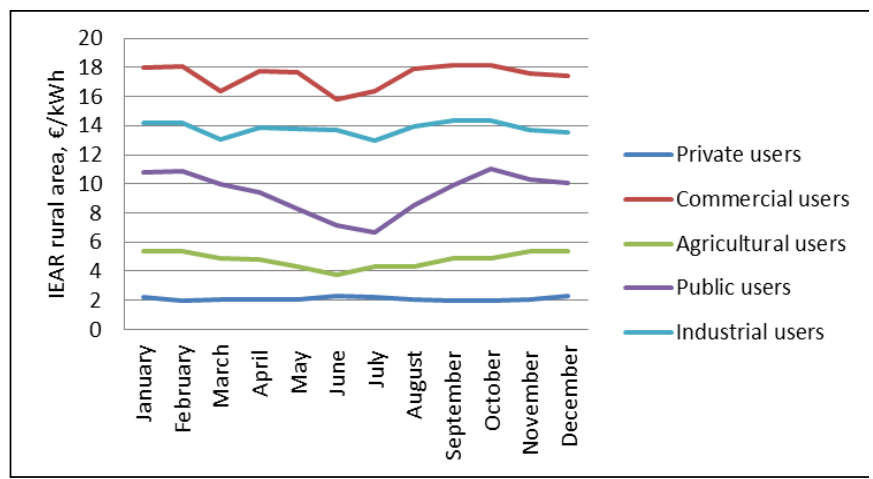

Fig. 6. IEAR in a urban area.

\section{B. Results of calculations of losses from interruptions by Monte Carlo method}

The purpose is to calculate the parameters of reliability and losses resulted from the interruptions. Application of Monte Carlo method gives an opportunity to obtained more accurate results using distribution of probabilities and reducing the number of assumptions. For an average electric supply model with one additional manually indicated power switch the total losses resulted from the interruptions are reduced for $14 \%$, for the models of rural areas - for $1.6 \%$, urban areas - for $19 \%$.
For an average electric supply model with two additional manually indicated power switches the total losses resulted from the interruptions are reduced for $19 \%$, for the models of rural areas - for $3.2 \%$, urban areas - for $19 \%$.

For an average electric supply model with three additional manually indicated power switches the total losses resulted from the interruptions are reduced for $22 \%$, for the models of rural areas - for $21 \%$, urban areas - for $22.8 \%$ (Fig. 7).

The optimal localization of the power switches in the network is a significant factor for improving of electric supply reliability and, therefore, decreasing of the losses from interruptions.

The absence of the optimal localization of sectioning

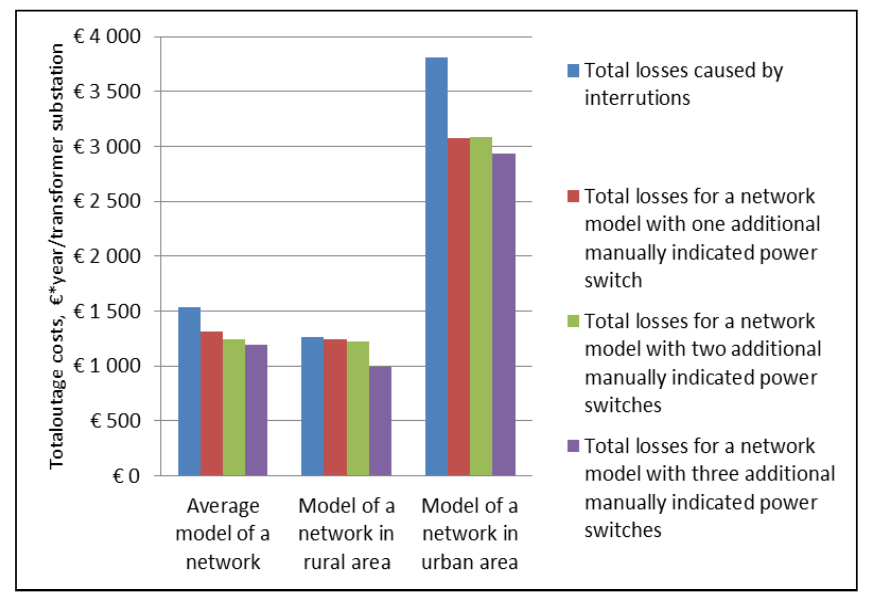

Fig. 7. The total losses resulting from interruptions.

elements in the network can cause an increasing or insignificant decreasing of the losses resulted from the interruptions as well as the manually indicated localizations of the sectioning elements do not give an opportunity to calculate the efficiency of capital investments for the reliability level increasing [8].

The reducing of the losses from interruptions are directly proportional to TS power, number of customers, consumption of electric energy and incomes of the customers.

C. Results of calculations of losses from interruptions by genetic algorithm with optimized numbers and localizations of power switches

The optimization of the number and localization of power switches in main and connecting lines is realized with the help of genetic algorithm for the electric supply network models of rural area, urban area and average type.

The total losses of the distribution network, society and customers resulted from the interruptions after the optimization of the number and localization of power switches and for different loan periods are given in Fig.8.

After the optimization of the number and localization of power switches for the case of no loan the losses resulted from the interruptions for the average network model are reduced for $14 \%$, for the model of rural area electric supply network - for $12.6 \%$, and for the urban area model - for $33.6 \%$.

Total losses from interruptions for the loan period of 10 years in the model of average network are reduced for $8 \%$, in the model of rural area network - for $7 \%$, and in the model of urban area - for $30 \%$. 
Total losses from interruptions for the loan period of 25 years in the model of average network are reduced for $5.8 \%$, in the model of rural area network - for $11 \%$, and in the model of urban area - for $20 \%$.

Summarizing the results we can conclude that for the models of average and rural areas electric supply networks the capital investments for the purchasing of power switches are proportionally decreased.

The total losses resulted from the interruptions are significantly decreased as a result of sectioning for the model

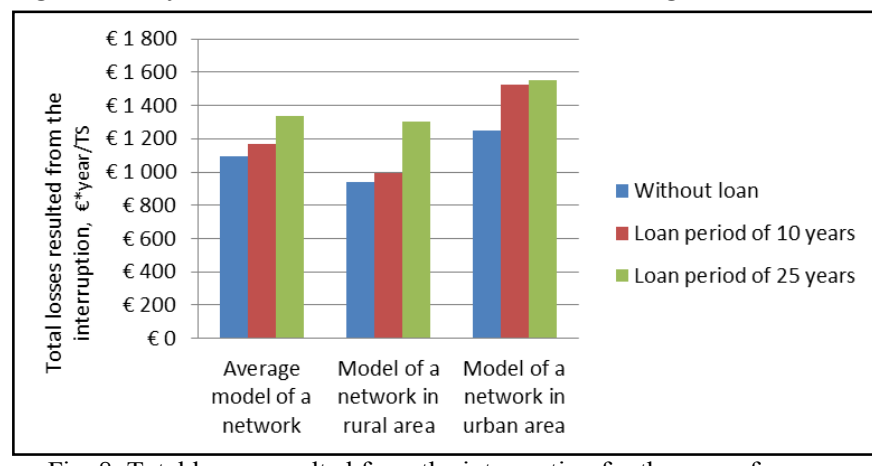

Fig. 8. Total losses resulted from the interruption for the case of power switches optimization.

of urban area electric supply network.

This is connected with higher consumption of electric energy in the urban regions and higher incomes of the customers [8].

Taking into account the total losses from the interruptions the additional connection of power switches can be considered from the smart grids development and maintaining easy point of view.

\section{Results of calculations of losses from interruptions by} genetic algorithm with optimized numbers and localizations of breakers

Note that the optimization of the number and localization of the breakers does not give an opportunity to achieve a minimum level of the losses resulting from the interruptions.

Besides, the correspondence of the optimal number of the breakers to that of the power switches, the breakers cannot provide the operation of the network without the interruptions that is why the minimized expenses include the customers' losses from the interruptions.

Fig.9. represents the total losses of the distribution network, customers and society for an optimal number of breakers for the loan period of 10years, 25 years and without the loan.

After the optimization of the number and localization of breakers for the case of no loan the losses resulted from the interruptions for the average network model are reduced for 2 $\%$, for the model of rural area electric supply network - for $1 \%$, and for the urban area model - for $9 \%$.

Total losses from interruptions for the loan period of 10 years in the model of average network are reduced for $6 \%$, in the model of rural area network - for $3 \%$, and in the model of urban area - for $9 \%$.

Total losses from interruptions for the loan period of 25 years in the model of average network are reduced for $8 \%$, in the model of rural area network - for $3 \%$, and in the model of urban area - for $7 \%$ (Fig. 9).

Taking into account the total losses from the interruptions, the additional connection of breakers can be considered from the perspective of smart grid development and easy maintenance.

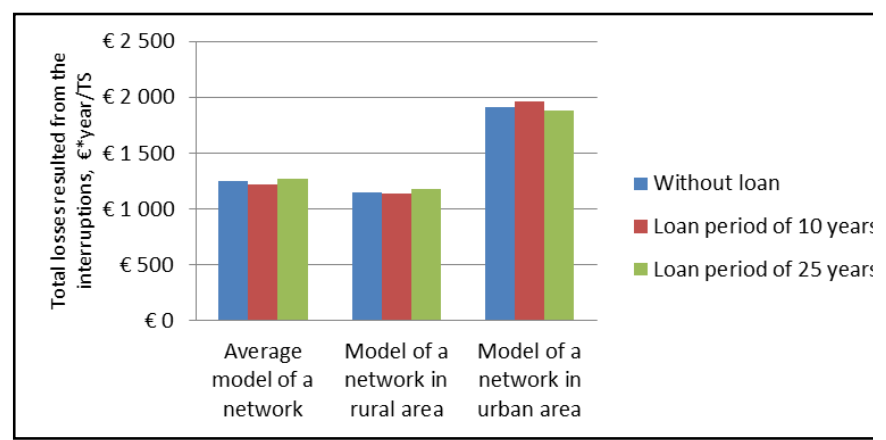

Fig. 9. Total losses resulted from the interruption for the case of breakers optimization.

\section{CONCLUSIONS}

The proposed methods can be applied for the calculations of the interruption risks of the customers and compensation of the losses resulted from the interruptions.

The possible future modifications of the proposed methods are applicable in the solutions of different problems related to the analysis of electric supply interruptions.

The overview, analysis and systematization of the methods of distribution networks reliability calculation, optimization methods of reliability improvement, the alternative of the reliability improvement and the losses resulted from the electric supply interruptions give an opportunity to search for the solutions of capital investments on the level of distribution networks, customers and society taking into account the tendencies of development and perspective technologies.

Optimization of the number of power switches and localization completed with the help of genetic algorithm, in accordance with the loan term and properties of the network model, allows reducing the losses from interruptions from 5.8 $\%$ to $33.6 \%$.

Optimization of the number of breakers and localization completed with the help of genetic algorithm, in accordance with the loan term and properties of the network model, allows reducing the losses from interruptions from $1 \%$ to $9 \%$.

The risks, losses, planning and advantages of the electric supply network should be analyzed in accordance with economic, environment, electric supply quality, probability of interruptions, the risks of the changes in legislation, etc.

Estimating the solutions of the electric supply reliability improvement most of the attention should be turned to the selection of optimal number and localization of the sectioning elements that provides an immediate improvement of the electric supply reliability.

Taking into account the total losses from the interruptions the additional connection of power switches and /or breakers can be considered from the smart grids development and easy maintenance point of view, but not from the losses decreasing 
point of view.

The volume of the possible losses resulted from interruptions can be variable with the increasing of electric energy consumption and/or changing of the customer properties.

\section{ACKNOWLEDGEMENT}

This research work has been supported by Latvian Council of Science (Project No. 673/2014). L. Zemite, J. Gerhards, M. Gorobetz, A. Levchenkov, Riga Technical University Faculty of Electrical and Power engineering, Riga, Latvia.

\section{REFERENCES}

[1] Brown R. E. Electric Power Distribution Reliability. - Marcel Dekker, New York, 2002. - p. 365.

[2] Alevehag K. Impact of Dependencies in Risk Assessments of Power Distribution Systems. - Licentiate Thesis, Royal Institute of Technology, School of Electrical Engineering, Electric Power Systems, Stockholm: Sweden, 2008. - p. 155.

[3] Helseth A. Modeling Reliability of Supply and Infrastructural Dependency in Energy Distribution Systems. - Thesis for the degree of philosophy doctor, Trondheim, Norwegian University of Science and Technology, 2008. - p. 132.

[4] Chayakulkheeree K. Economy of Power System Reliability. - A Training Workshop on Power System Economics and Planning, Asian Institute of Technology, 2006. - p. 68.

[5] Kjølle G. H., Samdal K., Singh B., Kvitastein O. A. Customer Costs Related to Interruptions and Voltage Problems: Methodology and Results. - Power Systems, IEEE Transactions on, vol.23, no.3, Aug. 2008. - pp. 1030. - 1038.

[6] Billinton R. Reliability of power supplies. In Electronics and Power , vol.24, no.4, , April 1978. - pp. 307. - 310.

[7] Theil A., Theil M. Medium Voltage network reliability: efficiency oriented supply restoration strategies. - 15th PSCC, Session 8, Paper 5, Liege, 2005. - pp. 1-6.

[8] Distribuzione C. N. Optimal Placement of Automation Devices in Enel Distribution Network. - in Electricity Distribution - Part 1, 2009. CIRED 2009. 20th International Conference and Exhibition, 8-11 June 2009. pp. 1. -4 .

[9] Haghifam M. R. Optimal allocation of tie points in radial distribution systems using a genetic algorithm.- Eur. Trans. Elect. Power, vol. 14, no. 2, 2004. - pp. 85. - 96 .

[10] Zemīte L., Gerhards J., Gorobecs M., Levčenkovs A. Optimization of Switch Allocation in Power Distribution Systems - International Workshop on Deregulated Electricity Market Issues (DEMSEE 2015), Ungārija, Budapešta, 2014.. - pp.166. - 173.

[11] Sljivac D., Nikolovski S., Kovac Z. Distribution Network Restoration Using Sequential Monte Carlo Approch. - The 9th International Conference on Probabilistic Methods Applied to Power Systems, June 11-15, 2006. - p. 6.

Laila Zemite is graduated $\mathrm{PhD}$ in 2016, assistant professor of Riga Technical University Institute of Power and Electrical Engineering. Results of research activity are published in various international scientific proceedings and journals in fields of distribution system reliability, power system development, planning and control. She is leader of various national projects and international projects.

Janis Gerhards is $\mathrm{PhD}$ professor, Riga Technical University, Institute of Institute of Power and Electrical Engineering. His fields of interests are optimization theory, reliability research in free electricity market conditions, distribution system reliability, automatization, power system development, planning and control. He was leading various national and international projects, author of many patents, books and publications.

Mikhail Gorobetz is graduated $\mathrm{PhD}$. in 2008, assistant professor and leading researcher of Riga Technical University Institute of Industrial Electronics and Electrical Engineering. Results of research activity are published in various international scientific proceedings and journals in fields of adaptive control, neural networks, genetic algorithms, modelling and simulation of dynamic processes. He is leader of various national projects and international projects. He is author of many study books and patented inventions.

Anatoly Levchenkov, $\mathrm{PhD}$ professor, Riga Technical University, Institute of Industrial Electronics and Electrical Engineering, Institute of Railway Transport. He got engineer diploma in electrical engineering in 1969, PhD degree in 1978. His fields of interests are optimization theory, group decision support systems, negotiation support systems, scheduling, logistics, intelligent transport systems, evolutionary algorithms for embedded systems. He was leading various national and international projects, author of many patents, books and publications. 